\title{
Dislocation glide and grain boundary decohesion in polycrystalline molybdenum disilicide during plastic deformation
}

\author{
L. Junker ${ }^{1}$, M. Bartsch, U. Messerschmidt * \\ Max-Planck-Institut für Mikrostrukturphysik, Weinberg 2, D-06120 Halle (Saale), Germany
}

Received 27 March 2001; received in revised form 15 June 2001

\begin{abstract}
Molybdenum disilicide polycrystals were deformed in constant strain rate tests in compression followed by analyses of the deformed specimens by means of optical microscopy and scanning and transmission electron microscopy. The strain rate sensitivity was measured by stress relaxation tests. Using a low strain rate of $2.5 \times 10^{-7} \mathrm{~s}^{-1}$, it was possible for the first time to achieve plastic flow at low-temperatures down to $495{ }^{\circ} \mathrm{C}$ and thus in the temperature range of the flow stress anomalies of different slip systems in single crystals. In addition, in situ straining experiments in a high-voltage electron microscope were performed to observe the deformation processes directly. The deformation is controlled by dislocation glide on the $\left\{\begin{array}{lllllllllllll}0 & 1 & 0\end{array}\right\}$ and $\left.\left\{\begin{array}{lllll}1 & 1 & 0\end{array}\right\}<\begin{array}{lll}1 & 1 & 1\end{array}\right\rangle$ slip systems below $1000{ }^{\circ} \mathrm{C}$, however, by visco-elastic grain boundary glide and decohesion above this temperature. (C) 2002 Elsevier Science B.V. All rights reserved.
\end{abstract}

Keywords: Molybdenum disilicide; Polycrystals; Plastic deformation; Electron microscopy

\section{Introduction}

For many high-temperature structural applications, materials are necessary combining excellent strength in a wide range of temperatures and a good oxidation resistance. Besides ceramics, some intermetallic compounds, particularly aluminides and silicides, are very promising candidates for these applications. Molybdenum disilicide $\left(\mathrm{MoSi}_{2}\right)$ has a very high melting temperature $\left(2030{ }^{\circ} \mathrm{C}\right)$, a good oxidation resistance and a high fracture toughness at high temperatures when it becomes ductile [1]. However, like other high-temperature materials, $\mathrm{MoSi}_{2}$ is very brittle at room temperature and has a low creep resistance at temperatures of ductility. To optimize structural materials based on $\mathrm{MoSi}_{2}$ an improved understanding of deformation processes in the matrix material is necessary.

$\mathrm{MoSi}_{2}$ crystallizes in a body-centred tetragonal structure $\left(\mathrm{C} 11_{\mathrm{b}}\right)$ with a high $c / a$ ratio of 2.45 . The plastic

\footnotetext{
* Corresponding author. Tel.: + 49-345-5582-927; fax: + 49-3455511-223.

E-mail address: um@mpi-halle.de (U. Messerschmidt).

${ }^{1}$ Present address: Media Print \& Online Systeme GmbH, Atriumstr. 1, Leipzig D-04315, Germany.
}

deformation properties of $\mathrm{MoSi}_{2}$ single crystals are therefore extremely anisotropic. It exists a hard orientation with the deformation axis along the tetragonal $c$ axis [0 0101$]$. Along this orientation, single crystals can be deformed only above $900{ }^{\circ} \mathrm{C}$ [2] by glide of dislocations with $1 / 2\langle 331\rangle$ Burgers vectors on $\left\{\begin{array}{lll}0 & 1 & 3\end{array}\right\}$ planes. For single crystals with orientations away from [0 01 l], i.e. along soft orientations, plastic flow is possible down to temperatures below room temperature [2]. Different operating slip systems were identified by different authors [2,3]. The $\left\{\begin{array}{lll}1 & 1 & 0\end{array}\right\}\left\langle\begin{array}{llll}1 & 1 & 1\end{array}\right\rangle$ and $\left\{\begin{array}{llll}0 & 1 & 1\end{array}\right\}\left\langle\begin{array}{llll}1 & 0 & 0\end{array}\right)$ systems are the easy slip systems for most orientations. All these slip systems show an anomalous increase of the flow stress with increasing temperature in different ranges between 600 and $1100{ }^{\circ} \mathrm{C}$ [2].

Polycrystalline $\mathrm{MoSi}_{2}$ was deformed at temperatures above $818{ }^{\circ} \mathrm{C}$ by different authors [4-6]. It was the aim of the present work to deform polycrystalline $\mathrm{MoSi}_{2}$ within a wide range of temperatures including lower temperatures to reach the range of the flow stress anomalies of slip in single crystals and to study the structure of the deformed samples by different microscopy techniques. Besides, the deformation processes at high temperatures were observed directly by in situ straining experiments in a high-voltage (transmission) 
electron microscope (HVEM) using a special tensile stage for high temperatures. Part of this work was published before in Ref. [7].

\section{Experimental}

The material tested was produced in the Fraunhofer Institute of Applied Materials Science, Dresden, by reaction sintering of mechanically pre-treated elemental powders followed by hot pressing at $1550{ }^{\circ} \mathrm{C}$, yielding a polycrystal of about $97.5 \%$ of the theoretical density. The average grain size of $40 \mu \mathrm{m}$ was determined by optical microscopy. The deformation tests were performed in compression along the hot-pressing direction in air in a digitally controlled single-screw testing machine at a constant strain rate of $2.5 \times 10^{-7} \mathrm{~s}^{-1}$. Such a low strain rate was chosen since, at high-temperatures, the material quickly disintegrated at higher strain rates. Temperature change and stress relaxation tests were conducted during the compression tests. The strain rate sensitivity $r$ of the flow stress $\sigma$ was determined by

$r=\mathrm{d} \sigma / \mathrm{d} \ln \dot{\varepsilon}_{\text {plast }}=\mathrm{d} \sigma / \mathrm{d} \ln (-\dot{\sigma})$,

from the slope of stress relaxation curves plotted as the logarithm of the relaxation rate versus the stress $\sigma$, where $\dot{\varepsilon}_{\text {plast }}$ is the plastic strain rate. Another parameter expressing the strain rate sensitivity is the stress exponent $m$ according to

$m=\mathrm{d} \ln \dot{\varepsilon}_{\text {plast }} / \mathrm{d} \ln \sigma=\mathrm{d} \ln (-\dot{\sigma}) / \mathrm{d} \ln \sigma$.

Supplementary tests were carried out under load control with loading and unloading sequences at a high stress rate of $50 \mathrm{~N} \mathrm{~s}^{-1}$ between creep phases in the loaded and unloaded conditions in order to separate the elastic, anelastic and plastic contributions of the strain as well as to determine the activation parameters of the creep deformation.

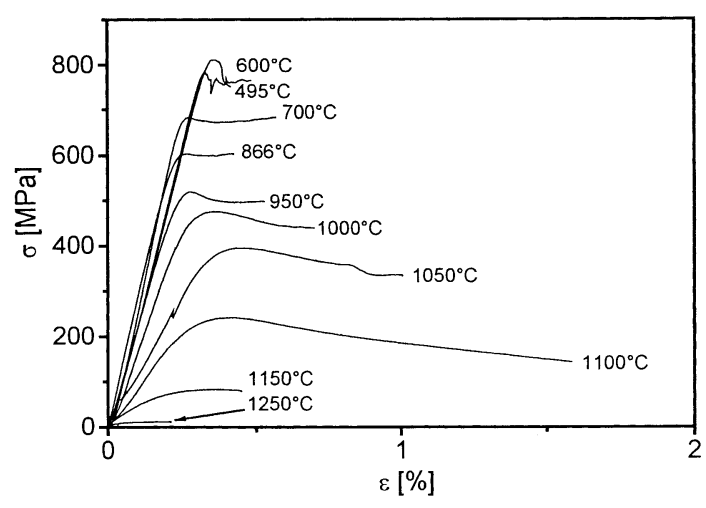

Fig. 1. Stress-strain curves at a strain rate of $2.5 \times 10^{-7} \mathrm{~s}^{-1}$ until the respective first stress relaxation tests.
The surfaces of deformed specimens were studied by optical microscopy to estimate the degree of deformation by the distribution of slip traces and cracks and by scanning electron microscopy (SEM) to determine the orientation of slip traces with respect to the orientation of the individual grains by electron back scattered diffraction (EBSD). To obtain stress free surfaces needed for useful EBSD the surfaces were etched by argon ions $(0.5 \mathrm{kV}, 0.1 \mathrm{~h})$ in perpendicular incidence. By this procedure, stress free etching dimples were generated for EBSD while the slip traces between the dimples were conserved.

Thin foils for transmission electron microscopy were prepared from the deformed specimens by cutting, polishing, dimpling and argon ion milling $(4 \mathrm{kV}, 20-60 \mathrm{~h}$, $13^{\circ}$ ), both perpendicular to the loading axis and parallel to it near the surface in order to obtain an area transparent to the electron beam close to an outer surface of the specimen. The dislocation structures inside the grains were studied by diffraction contrast analysis in a HVEM. The chemical composition near the grain boundaries was investigated by energy dispersive $\mathrm{X}$-ray (EDX) analysis in a transmission electron microscope (TEM) of higher resolution. In situ deformation experiments were performed in a HVEM in a special high-temperature straining stage [8].

\section{Results}

\subsection{Compression tests}

Plastic flow occurs at all selected temperatures from 495 to $1250{ }^{\circ} \mathrm{C}$. Fig. 1 presents the stress-strain curves up to the respective first stress relaxation test. Below $950{ }^{\circ} \mathrm{C}$, work hardening occurs beyond the yield point with a work hardening coefficient $\Theta$ of about $13 \mathrm{GPa}$ between 600 and $800{ }^{\circ} \mathrm{C}$. Above $950{ }^{\circ} \mathrm{C}$, however, softening takes place with $\Theta \cong-5 \mathrm{GPa}$ between 1050 and $1150{ }^{\circ} \mathrm{C}$. Fig. 2 shows the temperature dependence of the upper yield points. The flow stress $\sigma$ decreases continuously with increasing temperature, but the slope of the curve suggests three temperature ranges. (i) Below about $750{ }^{\circ} \mathrm{C}$, the temperature sensitivity $\Delta \sigma / \Delta T$ taken as an average slope amounts to about $-1 \mathrm{MPa}$ $\mathrm{K}^{-1}$. (ii) Between about 750 and $900{ }^{\circ} \mathrm{C}$, a weak plateau appears with a low temperature sensitivity. (iii) At higher temperatures, the flow stress decreases rapidly by $-3 \mathrm{MPa} \mathrm{K}^{-1}$ down to very low values so that the temperature sensitivity becomes small again. The temperature sensitivity was also determined from the change of the flow stress after temperature change tests as well as from the shift of stress relaxation curves measured at different temperatures, as described below. These data are collected in Fig. 3. It shows also a decrease of the temperature sensitivity of the flow stress 


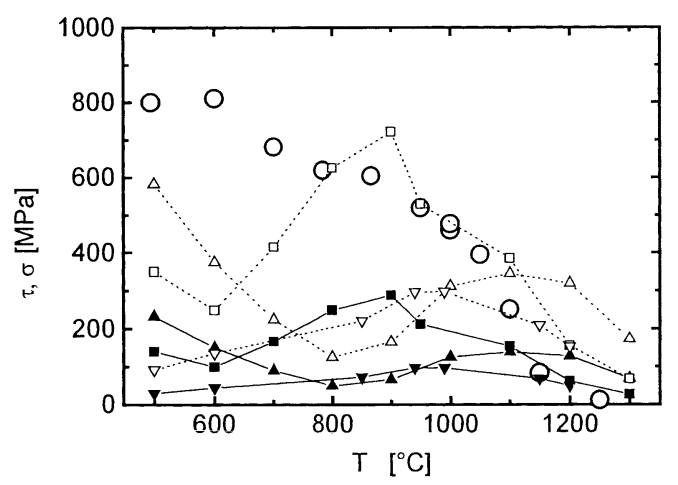

Fig. 2. Temperature dependence of the upper yield points of polycrystals at a strain rate of $2.5 \times 10^{-7} \mathrm{~s}^{-1}$ (large open circles) compared with the CRSS of single crystals for slip on $\left.\left\{\begin{array}{lllllllllll}0 & 1 & 1\end{array}\right\} \quad 0\right\rangle$ (solid squares and line) and $\left\{\begin{array}{lll}1 & 1 & 0\end{array}\right\}\left\langle\begin{array}{llll}1 & 1 & 1\end{array}\right\rangle$ (solid upwards triangles and line) at $10^{-4} \mathrm{~s}^{-1}$ after Ref. [2] as well as $\left\{\begin{array}{llllll}1 & 1 & 0\end{array}\right\}\left\langle\begin{array}{llll}1 & 1 & 1\rangle\end{array}\right.$ (solid downwards triangles and line) at $10^{-5} \mathrm{~s}^{-1}$ after Refs. [13,14]. The open squares and triangles with dotted lines show the respective shear stresses divided by an orientation factor of 0.4 .

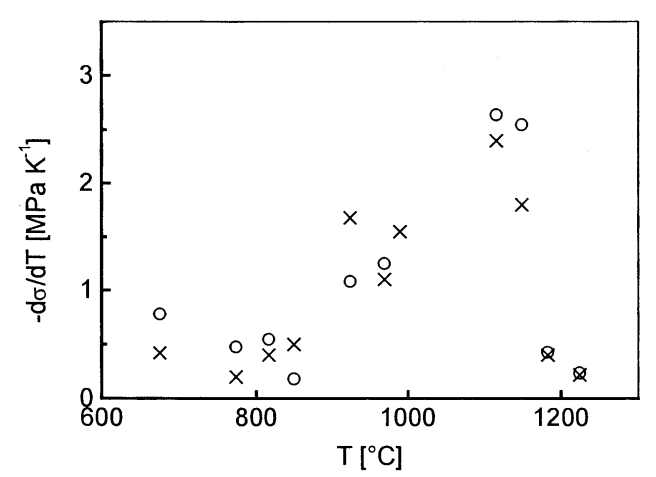

Fig. 3. Temperature sensitivity of the flow stress versus temperature. The data are calculated from the flow stress differences after temperature change tests (circles) and from the shift of stress relaxation curves taken at different temperatures (crosses).

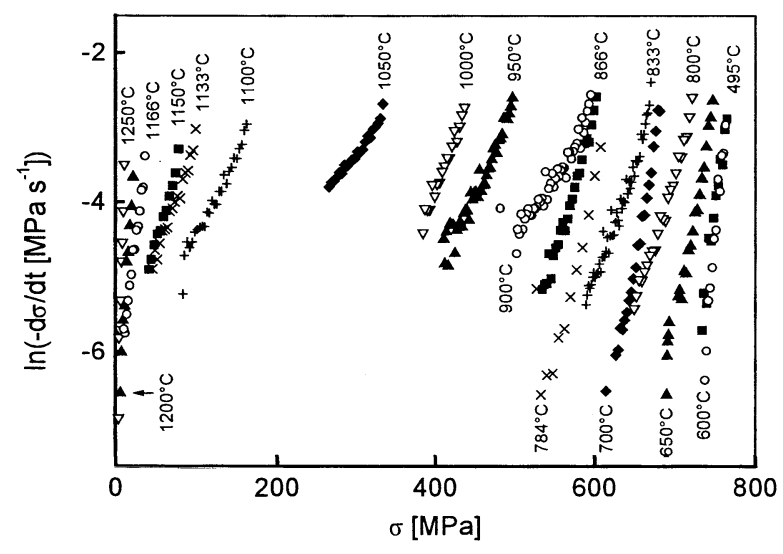

Fig. 4. Selected stress relaxation curves at different temperatures.

at increasing temperature with a minimum around $800{ }^{\circ} \mathrm{C}$ and a range of a high temperature sensitivity between about 950 and $1150{ }^{\circ} \mathrm{C}$.
Fig. 4 presents some typical stress relaxation curves at different temperatures in a plot of the logarithm of the relaxation rate versus the stress. Only the data of the first relaxations after the yield point are plotted. One way of determining the temperature sensitivity of the flow stress $\Delta \sigma / \Delta T$ consisted in taking the stress differences at the beginning of relaxations at different temperatures and dividing the stress difference by the respective temperature difference, as discussed already in connection with Fig. 3. The strain rate sensitivity $r$ of the flow stress can be calculated from Eq. (1). Fig. 5(a) presents the initial values at the beginning of the relaxation curves, which correspond to the strain rate prior to the relaxation tests, as a function of temperature. Below $900{ }^{\circ} \mathrm{C}$, the values scatter between 5 and 15 $\mathrm{MPa}$ depending on the strain and the plastic strain rate before the stress relaxation tests. Above $900{ }^{\circ} \mathrm{C}$, the strain rate sensitivity shows a pronounced maximum with values up to $50 \mathrm{MPa}$, in accordance with the temperature sensitivity in Fig. 3. Strain rate sensitivities $r$ can also be determined at lower strain rates by measuring the slope of the relaxation curves at lower relaxation rates. The relaxation rates can be converted into plastic strain rates considering that $\dot{\varepsilon}_{\text {plast }}=-\dot{\sigma} / S$, where $S$ is the stiffness of the specimen and the parts of the deformation machine within the strain gauge. Fig. 5(b) shows that $r$ decreases with increasing plastic strain rate. This behaviour originates from the bending of the relaxation curves in Fig. 4 away from the stress axis and is not consistent with usual obstacle mechanisms of
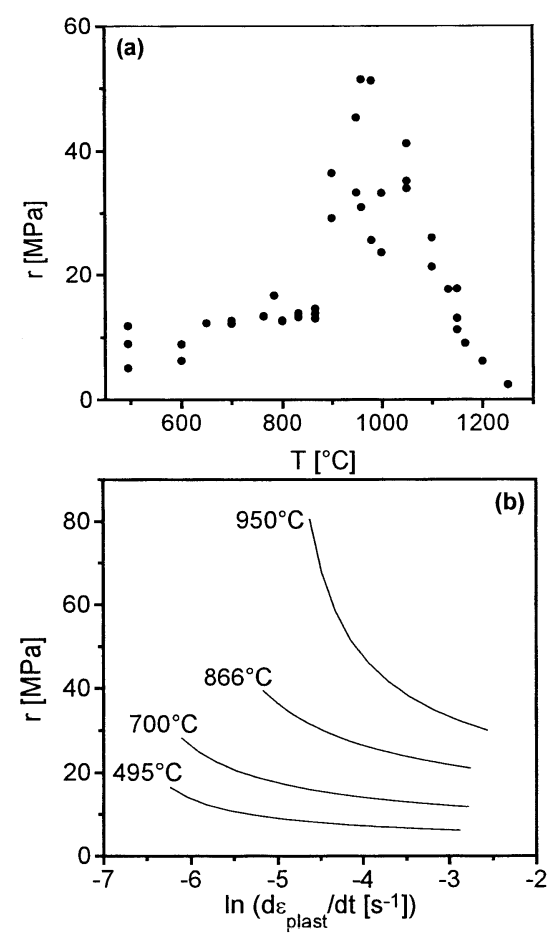

Fig. 5. Strain rate sensitivities $r$ of the flow stress in dependence of (a) the relaxation temperature, and (b) of $r$ on plastic strain rate. 

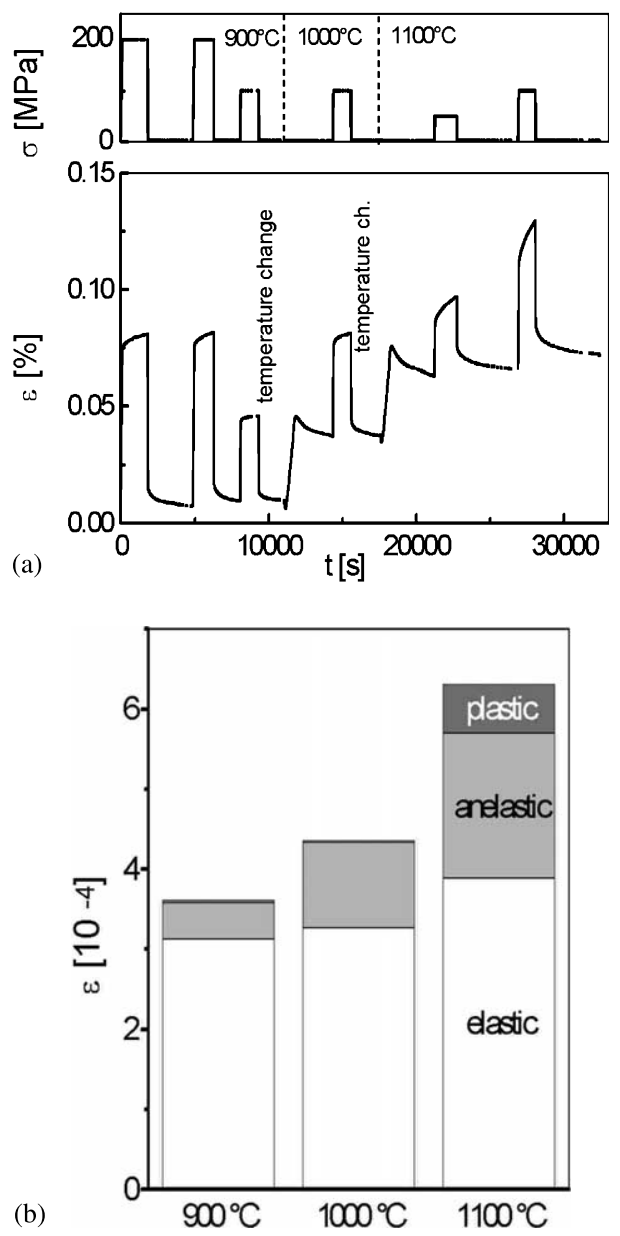

Fig. 6. Creep tests with loading and unloading cycles at different temperatures. (a) Dependence of stress and strain on time, and (b) elastic, anelastic and plastic contributions to the total strain at 900 , 1000 and $1100{ }^{\circ} \mathrm{C}$ at $100 \mathrm{MPa}$.

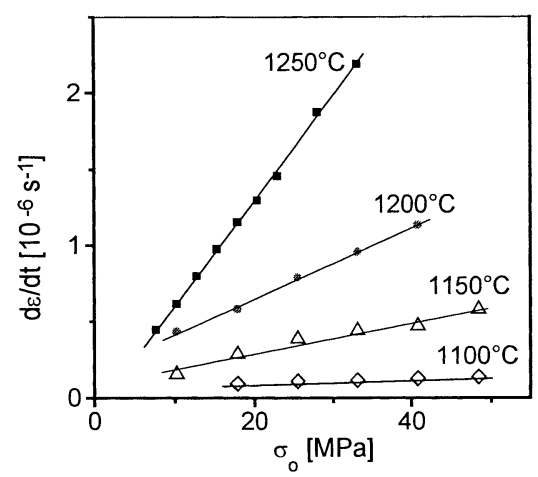

Fig. 7. Stress dependence of the steady-state creep rate at different temperatures above $1000{ }^{\circ} \mathrm{C}$.

the dislocation mobility. Therefore, the relaxation curves are characterized here by an 'inverse' curvature.

Creep experiments were performed in two different ways. In the first one, the specimen was cyclically loaded at the high rate of $50 \mathrm{MPa} \mathrm{s}^{-1}$, kept at a fixed load for some time and then unloaded again down to a low stress, as shown in Fig. 6(a). The stresses during loading were chosen to 200,100 or $50 \mathrm{MPa}$, i.e. stresses at which the specimen does not deform plastically at low-temperatures. These curves allow a separation of the elastic contributions to the strain appearing instantaneously, the anelastic contributions, which recover during the unloading phases, and the plastic contributions, which do not recover. The results of the tests at 900, 1000 and $1100{ }^{\circ} \mathrm{C}$ are presented in Fig. 6(b). The elastic strain increases slightly with temperature, which corresponds to a decrease of the elastic modulus from about $320 \mathrm{GPa}$ at $900{ }^{\circ} \mathrm{C}$ to about $260 \mathrm{GPa}$ at $1100{ }^{\circ} \mathrm{C}$. The anelastic strain increases strongly with temperature. At $1100{ }^{\circ} \mathrm{C}$, an irreversible plastic contribution to the total strain appears although the stress is still slightly lower than the flow stress at a strain rate of $2.5 \times 10^{-7} \mathrm{~s}^{-1}$.

In a second type of creep tests, the stress was increased stepwise at different temperatures and the creep curves were recorded until a steady-state creep rate occurred. These steady-state creep rates are plotted in Fig. 7 as a function of stress. From the proportionality of the creep rates and the stresses it follows that the stress exponent of the strain rate $m$ amounts to unity at all temperatures above $1000{ }^{\circ} \mathrm{C}$.

\subsection{Microstructure}

In the starting material, a grain boundary phase was not detected in TEM lattice images taken in a $200 \mathrm{kV}$ microscope. However, the EDX measurements of Fig. 8 taken in the same microscope demonstrate that iron, probably originating from the balls of the powder mills, has segregated at the grain boundaries leading to a reduction of the molybdenum content. These chemical gradients in the neighbourhood of the grain boundaries disappeared after high-temperature deformation.

The optical microscopy of surfaces of specimens deformed below $1050{ }^{\circ} \mathrm{C}$ showed slip steps indicating

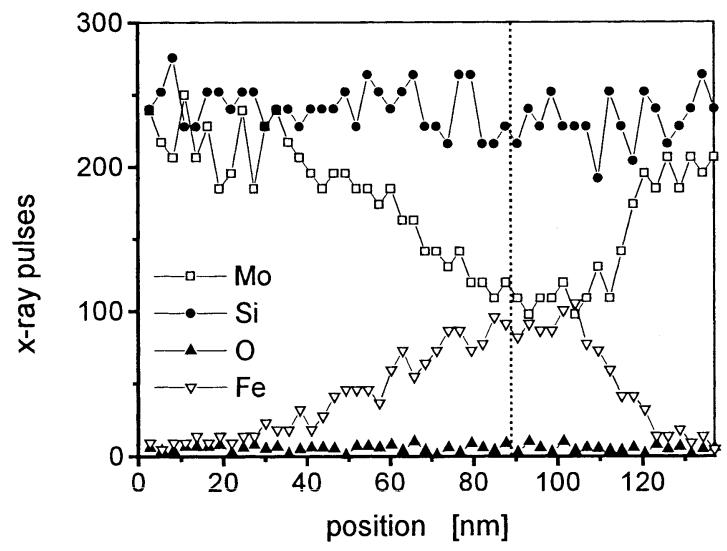

Fig. 8. Intensity of X-ray peaks during an EDX analysis of the undeformed material along a line across a grain boundary. 


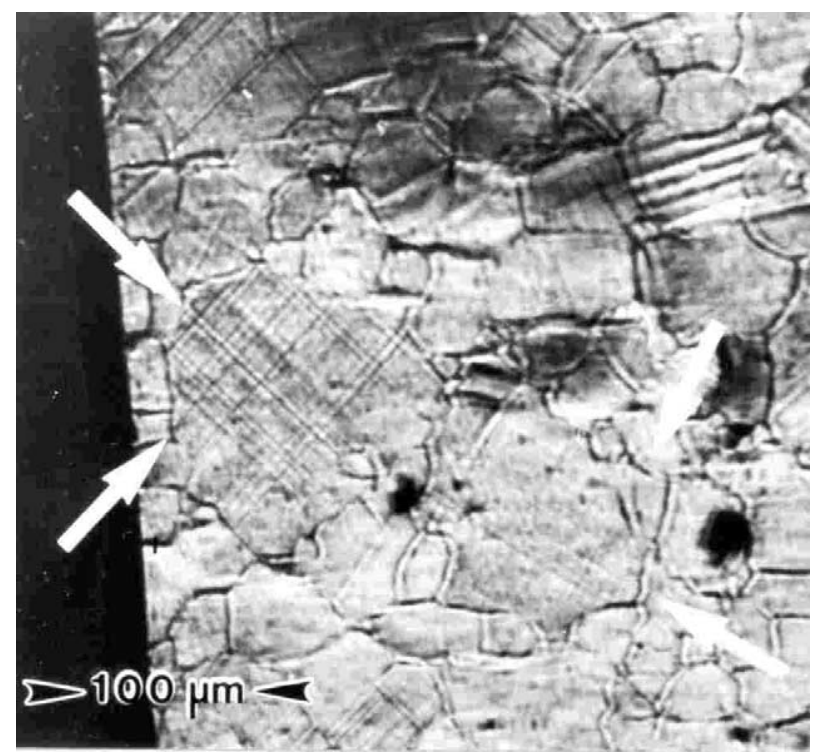

(a)

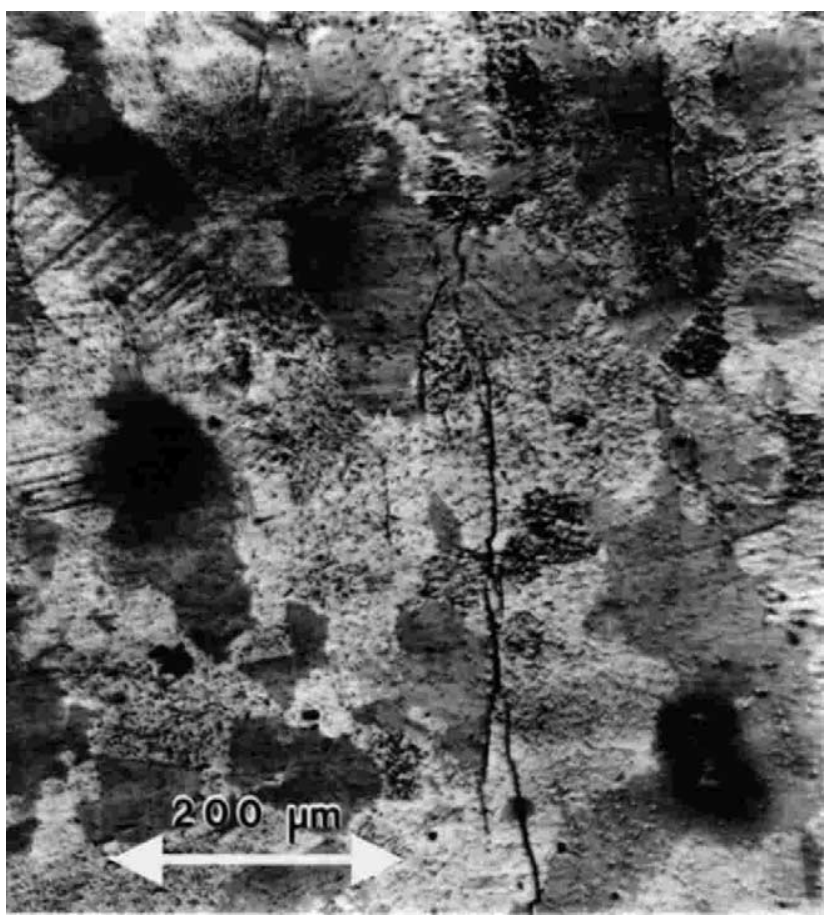

(b)

Fig. 9. Optical micrograph of deformed $\mathrm{MoSi}_{2}$. Specimen deformed at 1000,980 and $960{ }^{\circ} \mathrm{C}$ (a) and one deformed at $495{ }^{\circ} \mathrm{C}$ (b).

dislocation glide at these temperatures. Above $1050{ }^{\circ} \mathrm{C}$, slip traces were not observed. Between 900 and $1000{ }^{\circ} \mathrm{C}$, the slip traces appear on the surface of nearly all grains. Fig. 9(a) presents an example showing grains with two sets of crossing slip steps. At lower temperatures the number of slip traces decreases, but even at $495{ }^{\circ} \mathrm{C}$ some traces appear, as demonstrated on the left side of Fig. 9(b). At low-temperatures, only a single set of traces is found on the individual grains. The slip planes forming the slip traces were identified on speci- mens of three different deformation temperatures by indexing the specimen normal and the direction of 20 characteristic slip traces in the coordinates of the respective grains by EBSD in the SEM. This yields the indexes of the intersecting lines of the slip planes with the surfaces. Possible slip planes of lowest indexes containing the intersection lines were considered as the activated slip planes. Most of the traces fitted consistently to slip on $\left\{\begin{array}{llll}0 & 1 & 1\end{array}\right\}$ and $\left\{\begin{array}{lll}1 & 1 & 0\end{array}\right\}$ planes, independent of the deformation temperature. In some specimens, the dislocation structure was analysed in an HVEM. Fig. 10 presents a typical dislocation configuration. Groups of parallel dislocations appear between spherical $\mathrm{SiO}_{2}$ inclusions and the grain boundaries. The Burgers vectors were determined by contrast extinction using the $b \cdot g=0$ rule. The analysis showed that all dislocations belonged to the $\left\{\begin{array}{lllll}0 & 1 & 1\end{array}\right\}\left\langle\begin{array}{lll}1 & 0 & 0\end{array}\right\rangle$ slip system. According to the flow stress data of single crystals [2], the traces corresponding to $\left\{\begin{array}{lll}1 & 1 & 0\end{array}\right\}$ slip planes should originate from dislocations with $1 / 2\langle 1 \quad 11\rangle$ Burgers vectors. Thus, $\left\{\begin{array}{lll}0 & 1 & 1\end{array}\right\}\left\langle\begin{array}{lll}1 & 0 & 0\end{array}\right\rangle$ and $\left\{\begin{array}{lllll}1 & 1 & 0\end{array}\right\}\left\langle\begin{array}{llll}1 & 1 & 1\end{array}\right\rangle$ should be the relevant slip systems during the deformation of the present $\mathrm{MoSi}_{2}$ polycrystals.

At all temperatures, even at intermediate ones where slip traces occur on nearly every grain, intergranular cracks are observed. The density of cracks increases with decreasing temperature, and below $700{ }^{\circ} \mathrm{C}$ additional transgranular cracks appear as shown in the centre of Fig. 9(b). Above $1000{ }^{\circ} \mathrm{C}$, the density and width of intergranular cracks increase rapidly.

In contrast to the results of EDX in a TEM that the starting material does not contain a pronounced grain boundary phase, amorphous layers were observed in the SEM and the HVEM during and after deformation at high temperatures. Fig. 11 presents a micrograph taken during an in situ straining experiment in the HVEM at $1080{ }^{\circ} \mathrm{C}$. The amorphous phase is imaged in bright contrast using the so-called diffuse dark-field technique. An intergranular crack proceeds via the

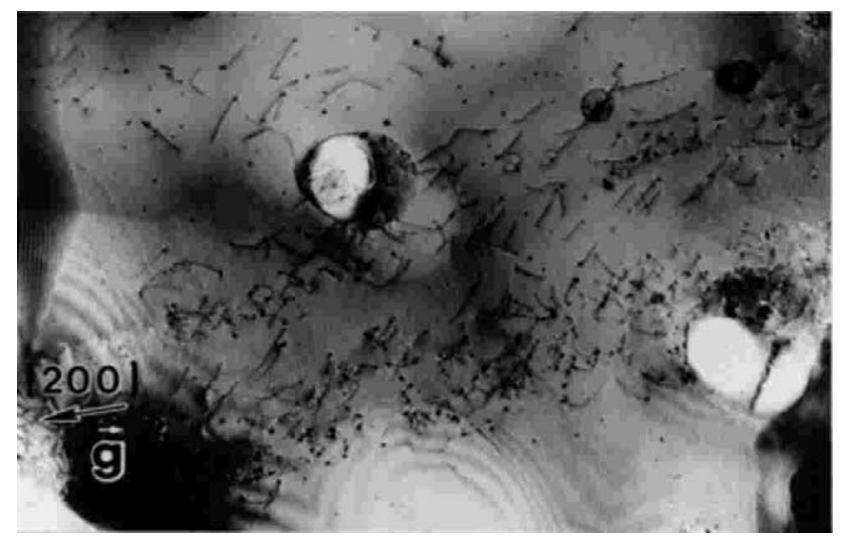

Fig. 10. HVEM micrograph of dislocations of a $\left\{\begin{array}{lllll}0 & 1 & 1\end{array}\right\}\left\langle\begin{array}{llll}1 & 0 & 0\end{array}\right\rangle$ slip system in $\mathrm{MoSi}_{2}$ deformed at $1000{ }^{\circ} \mathrm{C}$. 


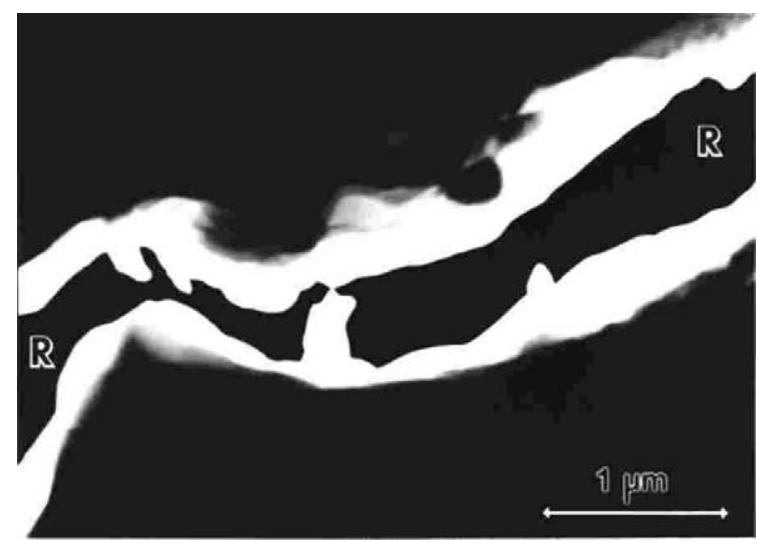

Fig. 11. Micrograph of the amorphous phase along an intergranular crack $(\mathrm{R}-\mathrm{R})$ produced during in situ deformation in an HVEM imaged in bright contrast by the diffuse dark-field technique.

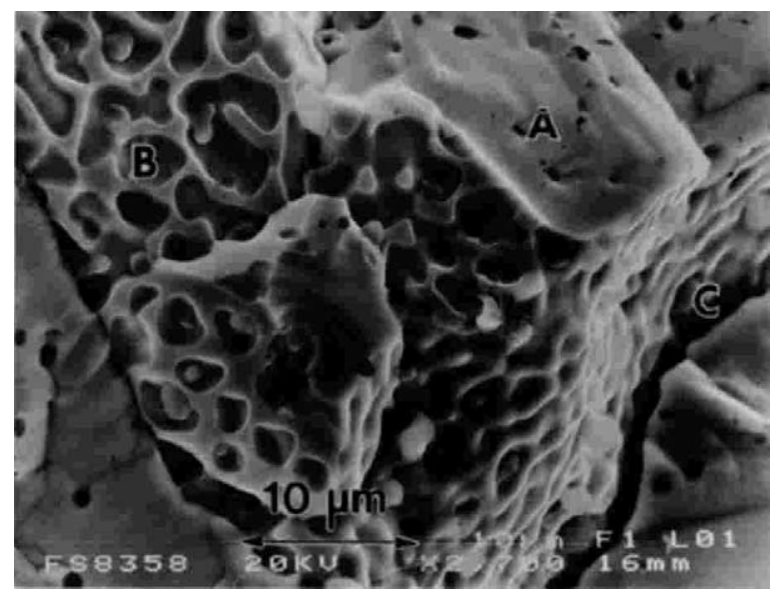

Fig. 12. SEM micrograph of a specimen deformed at $1200{ }^{\circ} \mathrm{C}$ followed by brittle fracture at room temperature.

formation and growth of voids in the amorphous phase along the grain boundaries. A similar conclusion can be drawn from Fig. 12 showing a SEM micrograph of a specimen deformed at $1200{ }^{\circ} \mathrm{C}$ followed by brittle fracture at room temperature. The structure of the fracture surface reflects the different stages of the intergranular cracking. At A, the grain boundary layer is broken in a brittle way at room temperature showing a smooth face. At $\mathrm{B}$, the decohesion has began at $1200{ }^{\circ} \mathrm{C}$, but the bridges between the voids are fractured only at room temperature. Finally, the area $\mathrm{C}$ presents a look into an interior crack where the decohesion was completed at high temperature so that the former bridges between the voids are already rounded.

\section{Discussion}

From both the macroscopic temperature and strain rate sensitivity of the flow stress and from the observa- tion of the microstructures, two temperature ranges can be distinguished with different deformation mechanisms of the present reaction sintered polycrystalline $\mathrm{MoSi}_{2}$. Up to $1050{ }^{\circ} \mathrm{C}$, slip inside the grains is proved by optical and SEM and will be the dominating deformation mechanism. In the undeformed condition, the material does not contain a pronounced grain boundary phase. The increased iron concentration near the grain boundaries may diffuse away at elevated temperatures. However, during the exposition to high temperatures and deformation, an amorphous grain boundary phase forms. Possibly, processes of stress corrosion are involved in the formation of this phase. Below about $950{ }^{\circ} \mathrm{C}$, the viscosity of this phase is high enough to prevent remarkable grain boundary flow. Thus, stresses can build up necessary to activate slip inside the grains. Above $1000{ }^{\circ} \mathrm{C}$, however, the viscosity of the grain boundary phase decreases so that deformation occurs by grain boundary flow before the stress necessary for plastic flow is reached inside the grains. This is accompanied with a rapid degradation of the strength properties of the material. In the following, the two temperature ranges are discussed separately.

\subsection{Low-temperature range}

For the first time, polycrystalline $\mathrm{MoSi}_{2}$ without additions has been plastically deformed below about $800{ }^{\circ} \mathrm{C}$. Otherwise, low temperatures deformation of $\mathrm{MoSi}_{2}$ materials even down to room temperature was recently achieved in the quaternery alloy $\mathrm{MoSi}_{2}-1$ at.\% $\mathrm{Re}-2 \mathrm{at} . \% \mathrm{Al}[9]$. The softening results from the addition of $\mathrm{Al}$, as shown previously for single crystals [10]. It was shown by transmission electron microscopy and the analysis of slip steps on the surface that $\left\{\begin{array}{lll}0 & 1 & 1\end{array}\right\}\left\langle\begin{array}{lll}1 & 0 & 0\end{array}\right\rangle$ and $\left\{\begin{array}{lllll}1 & 1 & 0\end{array}\right\}\left\langle\begin{array}{lll}1 & 1 & 1\end{array}\right\rangle$ slip systems were activated during deformation at temperatures below about $1000{ }^{\circ} \mathrm{C}$. The fact that the slip traces on the surfaces can be resolved by optical microscopy points to planar glide, i.e. many dislocations glide on a single or closely spaced planes. This agrees with the observation of localized dislocation sources operating in single crystals at about $1000{ }^{\circ} \mathrm{C}$, emitting a great number of dislocations on the same slip plane [11]. It can be shown by the method of Groves and Kelly [12] that the von Mises criterion necessary for general slip in a polycrystal is not satisfied by the observed two types of slip systems. Thus, intergranular cracks are generated between grains in orientations, which do not allow slip transfer of all strain components. Due to these cracks, the critical shear stresses for glide of dislocations of

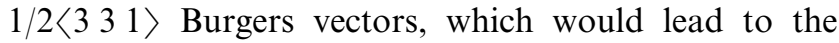
five independent slip systems, are not transmitted to grains in hard orientations. Accordingly, these dislocations are not activated in polycrystals. 
Fig. 2 compares the temperature dependence of the flow stress of polycrystals with the critical resolved shear stresses (CRSS) of the relevant slip systems in single crystals. The large open circles represent the upper yield points of polycrystals, the curves with solid symbols and lines, the CRSS after Ref. [2] for the $\left\{\begin{array}{lll}0 & 1 & 1\end{array}\right\}\left\langle\begin{array}{lll}1 & 0 & 0\end{array}\right\rangle$ and $\left.\left\{\begin{array}{llllll}1 & 1 & 0\end{array}\right\}<\begin{array}{llll}1 & 1 & 1\end{array}\right\rangle$ slip systems and after Refs. [13,14] for the $\left\{\begin{array}{lll}1 & 1 & 0\end{array}\right\}\left\langle\begin{array}{lll}1 & 1 & 1\rangle\end{array}\right\rangle$ system. Since the strain rates are different in the different experiments $\left(2.5 \times 10^{-7} \mathrm{~s}^{-1}\right.$ in the present study, $10^{-4} \mathrm{~s}^{-1}$ in Ref. [2] and $10^{-5} \mathrm{~s}^{-1}$ in Refs. [13,14]), the comparison is only of qualitative nature. The curves with small open symbols and dotted lines represent the CRSS of single crystals divided by an orientation factor of $m_{\mathrm{s}}=0.4$. This orientation factor may correspond to the situation of slip occurring in grains with a favourable orientation for the two easy systems better than the Taylor factor. The figure demonstrates that the position of the plateau of the flow stress of polycrystals corresponds well to the flow stress anomaly range of the $\left\{\begin{array}{llllll}0 & 1 & 1\end{array}\right\}\left\langle\begin{array}{llll}1 & 0 & 0\end{array}\right\rangle$ slip system after Ref. [2] and the $\left\{\begin{array}{lllll}1 & 1 & 0\end{array}\right\}\left\langle\begin{array}{llll}1 & 1 & 1\end{array}\right\rangle$ system after Refs. [13,14] but not to the latter system after Ref. [2]. The flow stress value of the polycrystalline material between about 800 and $1000{ }^{\circ} \mathrm{C}$ is slightly higher than the average of the single crystal CRSS data divided by $m_{\mathrm{s}}=0.4$. Thus, in the range where polycrystal deformation is controlled by glide of dislocations, the flow stress can roughly be explained by the CRSS of single crystals. The flow stress anomaly of the easy slip systems in single crystals is expressed as the plateau in the polycrystal data. The origin of the flow stress anomaly in $\mathrm{MoSi}_{2}$ is discussed elsewhere [14-17].

The flow stress of polycrystals does not follow the flow stress minima of the easy slip systems of single crystals at decreasing temperature. The higher stresses may have two reasons. First, polycrystals will have a higher concentration of impurities than single crystals. These impurities may give rise to an increasing contribution to the flow stress by solution hardening at decreasing temperatures. This is corroborated by different values of the strain rate sensitivity $r$. Fig. 5(a) shows constant strain rate sensitivities of about $10 \mathrm{MPa}$ below about $900{ }^{\circ} \mathrm{C}$ while single crystals have very low or even negative values in the anomaly range $[13,14] . r$ values of $10 \mathrm{MPa}$ at $900{ }^{\circ} \mathrm{C}$ yield activation volumes $V=k T /\left(m_{\mathrm{s}} r\right)$ of the order of magnitude of $4 \times 10^{-27}$ $\mathrm{m}^{3}$ ( $k$ is the Boltzmann constant). These volumes correspond to impurity concentrations in the $100-\mathrm{ppm}$ range. It may be iron diffused into the grains from the grain boundaries. The second reason for the high stresses at low temperatures may consist in the formation of pileups of dislocations near the grain boundaries if only a single slip system of lowest CRSS can be activated in each grain so that slip transfer across the boundaries mostly becomes impossible. These stresses are finally relieved by an increasing amount of crack formation at decreasing temperatures.
An experimental activation energy $Q$ can be calculated from the temperature sensitivity of Fig. 3 and the strain rate sensitivity of Fig. 5(a) according to

$Q=-\left.\frac{k T^{2} \Delta \sigma}{r \Delta T}\right|_{\dot{\varepsilon}}$

The activation energy decreases from about $4.6 \mathrm{eV}$ at $680{ }^{\circ} \mathrm{C}$ down to about $2.6 \mathrm{eV}$ at $830{ }^{\circ} \mathrm{C}$. For a single thermally activated process, $Q$ should increase with increasing temperature. In single crystals, the activation energy amounts to about $2 \mathrm{eV}$ in the range of the normal low-temperature increase of the flow stress, i.e., below $500{ }^{\circ} \mathrm{C}$ [13]. In the range of the flow stress anomaly between 500 and $1000{ }^{\circ} \mathrm{C}$, the activation energy according to Eq. (3) is meaningless. From the high values of the flow stress, the decreasing values of $Q$ with increasing temperature and from the higher values of $r$ and $Q$ in polycrystals with respect to single crystals it may be concluded that different processes contribute to the flow stress of polycrystals in addition to those operating in the easy slip systems of single crystals. As discussed above, these processes may originate from a higher impurity concentration.

\subsection{High temperatures}

Above $1000{ }^{\circ} \mathrm{C}$, the microstructure observations of missing slip steps on the surface of the grains as well as fracture surfaces and in situ straining experiments in the HVEM showing flow of a grain boundary phase suggest that at these temperatures the deformation of polycrystals does not take place within the grains but by viscous processes in the grain boundary phase forming during high-temperature deformation. This conclusion is supported by the macroscopic deformation data, i.e. by an increasing amount of anelastic deformation (Fig. 6(b)), by a rapid decrease of the yield stress with increasing temperature below the stress levels corresponding to the easy slip systems in single crystals (Fig. 2), by softening after the upper yield point (Fig. 1) and by very large values of both the temperature and the strain rate sensitivity of the flow stress (Figs. 3 and 5(a)).

The steady-state creep data of Fig. 7 can be interpreted in terms of a creep law

$\dot{\varepsilon}_{\mathrm{ss}}=\frac{A \mu}{k T} D_{\mathrm{o}} \exp \left(\frac{Q}{k T}\right)\left(\frac{\sigma}{\mu}\right)^{m}$,

where $A$ is a constant, $\mu$ is the shear modulus, and $D_{\text {o }}$ is the pre-exponential factor of the diffusion coefficient and $Q$ an effective activation energy. Since in the present data $m=1, \mu$ cancels in Eq. (4). The stress exponent of $m=1$ does not agree with values determined from stress relaxation tests by Eq. (2) decreasing from about 10 at $1000{ }^{\circ} \mathrm{C}$ down to about 2.5 above $1150{ }^{\circ} \mathrm{C}$ [7]. The reason may be that anelasticity con- 
tributes to the strain rate during the relaxation tests with varying stress, while Eq. (2) is based on plastic deformation, only. Besides, damage processes contribute to the deformation, as discussed below. Stress exponents greater than unity were also observed in Refs. $[4,18,19]$. The activation energy $Q$ was determined from the data of Fig. 7 by plotting $\ln (\dot{\varepsilon}, T)$ versus $1 / T$. The activation energy increases from $2.7 \mathrm{eV}$ at a creep stress of about $10 \mathrm{MPa}$ to $3.9 \mathrm{eV}$ at $41 \mathrm{MPa}$. These values are in the range of previous literature data $[4,18,20]$. An increasing energy at increasing stress indicates again that the controlling process may change. Activation energies can also be determined from the temperature sensitivity of Fig. 3 and the strain rate sensitivity of Fig. 5(a) according to Eq. (3), as described for the low-temperature range. While below $1000{ }^{\circ} \mathrm{C}$, these activation energies have reasonable values, they amount to more than $10 \mathrm{eV}$ in the high-temperature range. The reason is certainly again connected with the damage processes occurring at the higher strain rates of the constant strain rate tests. If the deformation occurs inside the grains, the activation energy of creep should be equal to the diffusion energy of the slowly moving component of the material. Very little is known about the diffusion coefficients in $\mathrm{MoSi}_{2}$. Silicon vacancies are mobile so that they start to anneal out at $240 \mathrm{~K}$ [21]. Formation energies were only calculated [22]. According to that, they should be very high for the molybdenum and silicon vacancies (12 and $5.8 \mathrm{eV})$. Thus, in the high-temperature range, the creep deformation of the present material is certainly not controlled by bulk diffusion processes.

In the case of linear flow

$$
\sigma=\eta \dot{\varepsilon}
$$

where viscosity values $\eta$ can be calculated from the steady-state creep data of Fig. 7. The values of $\eta$ increase from $1.4 \times 10^{13} \mathrm{~Pa}$ s at $1250^{\circ} \mathrm{C}$ to $4 \times 10^{14} \mathrm{~Pa}$ $\mathrm{s}$ at $1100{ }^{\circ} \mathrm{C}$. The viscous processes occur in the grain boundary phase. Since the strain rates in the grain boundary phase are higher than the total strain rate, the $\eta$ values may be considered lower limits of the viscosity of the grain boundary phase. Its drastic decrease should be responsible for the strong decrease of the flow stress in the high-temperature range. Also, the activation energy of creep determined above should correspond to processes in the grain boundary phase.

The grain boundary deformation is accompanied by grain boundary decohesion since voids are formed along the grain boundaries as demonstrated by Figs. 11 and 12. It may therefore be responsible for the softening observed at high temperatures. Power law creep including cavitation may be described by adding a damage parameter $\rho$ to Eq. (4) (Ref. [23] extended to greater densities of cavitating facets in Ref. [24]). At constant temperature, the equation may then read as
$\dot{\varepsilon}=\frac{B \sigma^{m}}{1-\rho}$

where $B$ is a constant. The damage parameter may evolve with strain according to Ref. [25]

$\rho=\left(\varepsilon / \varepsilon_{\mathrm{f}}\right)^{\gamma}$,

where $\varepsilon_{\mathrm{f}}$ is the fracture strain and $\gamma$ an adjustable parameter. The assumption of a definite fracture strain corresponds to the fact that the material loses its internal coherence at some per cent of strain even under compression. For linear evolution of $\rho(\gamma=1)$, which is consistent with the stress-strain curves at small strains, and $m=1$, Eqs. (6) and (7) yield for the softening $\Theta=-\sigma_{0} / \varepsilon_{\mathrm{f}}$, where $\sigma_{0}$ is the stress at zero strain, which approximately equals the upper yield stress. The experimental value of $\Theta \cong-5 \mathrm{GPa}$ requires $\varepsilon_{\mathrm{f}}=6 \%$ for the curve at $1100{ }^{\circ} \mathrm{C}$, which is a very realistic value of the fracture strain. The damage can be regarded as a reduction of the load carrying specimen cross-section owing to the generated cracks. The microstructure of deformed specimens was studied at strains between 1 and $2 \%$, which corresponds to a reduction of the load carrying cross-section by about $25 \%$, or, at an average grain size of $40 \mu \mathrm{m}$, to a crack width of about $10 \mu \mathrm{m}$. Such values were observed in the SEM studies. Thus, the softening of the material during deformation above $1000{ }^{\circ} \mathrm{C}$ by grain boundary decohesion can well be interpreted by the usual concepts of damage mechanics. With increasing temperature, these damage processes become more and more important during deformation at a constant strain rate, even at the very low one of $2.5 \times 10^{-7} \mathrm{~s}^{-1}$. This may explain the large differences between the activation parameters measured during creep at low stresses and strains, where damage processes are not important, and deformation at a constant (mostly higher) strain rate with increasing damage at increasing temperatures.

\section{Conclusions}

For the first time, polycrystalline $\mathrm{MoSi}_{2}$ was deformed down to $495{ }^{\circ} \mathrm{C}$. Below about $1000{ }^{\circ} \mathrm{C}$, the deformation occurs by glide of dislocations on $\left\{\begin{array}{lllll}1 & 1 & 0\end{array}\right\}\left\langle\begin{array}{llll}1 & 1 & 1\end{array}\right\rangle$ and $\left\{\begin{array}{lllll}0 & 1 & 1\end{array}\right\}\left\langle\begin{array}{llll}1 & 0 & 0\end{array}\right\rangle$ slip systems.

A plateau in the flow stress versus temperature curve can be assigned to the anomalous temperature dependence of the CRSS of the respective slip systems in single crystals. The difference between the flow stress of the polycrystalline material and the single crystal data divided by the orientation factor at low-temperatures as well as the different values of the activation volume and the activation energy can be explained by a higher impurity content of the polycrystals.

As the von Mises criterion is not satisfied by the two types of slip systems, the deformation cannot be homo- 
geneous and microcracks are formed, most pronounced at the lowest temperatures as intergranular and transgranular cracks.

Above $1000{ }^{\circ} \mathrm{C}$, the viscosity of a forming grain boundary phase becomes so low that deformation occurs by grain boundary slide and decohesion. The stress exponent is then equal to unity. The softening which is observed after the upper yield point can be explained by usual concepts of damage mechanics.

\section{Acknowledgements}

The authors thank Dr R. Scholl, Fraunhofer Institute of Applied Materials Science, for supplying the specimen, Dr W. Tirschler, Technical University of Dresden, for performing the EBSD measurements and Ch. Dietzsch and W. Greie for technical help. Financial support by the Volkswagenstiftung is gratefully acknowledged.

\section{References}

[1] A.K. Vasudévan, J.J. Petrovic, Mat. Sci. Eng. A155 (1992) 1.

[2] K. Ito, T. Yano, T. Nakamoto, H. Inui, Y. Shirai, M. Yamaguchi, Intermetallics 4 (1996) 119.

[3] S.A. Maloy, T.E. Mitchell, A.H. Heuer, Acta Metall. Mater. 43 (1995) 657.
[4] A.K. Ghosh, A. Basu, Mat. Res. Soc. Symp. Proc. 322 (1994) 215.

[5] H. Chang, R. Gibala, Mat. Res. Soc. Symp. Proc. 322 (1994) 223.

[6] D.A. Hardwick, P.L. Martin, Mat. Res. Soc. Symp. Proc. 322 (1994) 209.

[7] L. Junker, M. Bartsch, U. Messerschmidt, Mat. Res. Soc. Symp. Proc. 552 (1999) KK5.23.1.

[8] U. Messerschmidt, M. Bartsch, Ultramicroscopy 56 (1994) 163.

[9] A.A. Sharif, A. Misra, J.J. Petrovic, T.E. Mitchell, Scripta Mater. 44 (2001) 879.

[10] H. Inui, K. Ishikawa, M. Yamaguchi, Intermetallics 8 (2000) 1131.

[11] S. Guder, M. Bartsch, M. Yamaguchi, U. Messerschmidt, Mater. Sci. Eng. A261 (1999) 139.

[12] G.W. Groves, A. Kelly, Phil. Mag. 8 (1963) 877.

[13] S. Guder, Doctoral Thesis, Martin-Luther-Universität Halle/Wittenberg, 2000.

[14] U. Messerschmidt, S. Guder, L. Junker, M. Bartsch, M. Yamaguchi, Mater. Sci. Eng. A 319-321 (2001) 342.

[15] U. Messerschmidt, M. Bartsch, S. Guder, D. Häussler, R. Haushälter, M. Yamaguchi, Intermetallics 6 (1998) 729.

[16] U. Messerschmidt, M. Bartsch, S. Guder, D. Häussler, Mat. Res. Soc. Symp. Proc. 552 (1999) KK10.9.1.

[17] U. Messerschmidt, S. Guder, D. Häussler, M. Bartsch, Mat. Res. Soc. Symp. Proc. 646 (2001) Y11.6.1.

[18] K. Sadananda, H. Jones, J. Feng, J.J. Petrovic, A.K. Vasudevan, Ceram. Eng. Sci. Proc. 12 (1991) 1671.

[19] C.R. Feng, K. Sadananda, Mat. Res. Symp. Proc. 364 (1995) 1053.

[20] S. Bose, Mater. Sci. Eng. A155 (1992) 217.

[21] K. Matsuda, Y. Shirai, M. Yamaguchi, Intermetallics 6 (1998) 395.

[22] M.I. Baskes, Mater. Sci. Eng. A261 (1999) 165.

[23] J.W. Hutchinson, Acta Metall. 31 (1983) 1079.

[24] H. Riedel, Fracture at High Temperatures, Springer, Berlin, 1987.

[25] H. Riedel, Fracture Mechanics, Habilitationsschrift, Scientific Report W 3/92, Fraunhofer Institut für Werkstoffmechanik, Freiburg 1992. 